\title{
Pensar con sonidos. Los universos musicales en El Trino del Diablo de Daniel Moyano.
}

\section{Thinking with Sounds. Musical Universes in El Trino del Diablo by Daniel Moyano.}

\section{Resumen}

La música ocupa un lugar predominante en la producción literaria de Daniel Moyano. Su escritura entrama en diversos planos -semántico, formal, ideológico- referencias y procedimientos provenientes del discurso musical construyendo un espacio textual complejo. Consideramos por ello que a través de su estudio es posible colaborar en la reflexión acerca de las múltiples formas de producción de sentido que se generan en el diálogo entre lenguajes artísticos, en este caso entre música y literatura.

En este trabajo realizamos una lectura de El trino del diablo para mostrar las formas en que el universo narrativo de la novela se configura a través de la incorporación de mitos y concepciones acerca de la música y los intérpretes, incidiendo en la construcción de espacios de pertenencia y marcos de referencia cultural e identitaria. Asimismo, la lectura en torno a la textualización de prácticas, valores y referencias musicales constituye una forma posible de conocimiento y comprensión del mundo político y social de los años 1970 en Argentina.

Palabras claves Música, literatura, identidad, poder.

\begin{abstract}
Music plays a major role in Daniel Moyano's literary production. References and procedures coming from musical discourse are interwoven in his writing creating a complex textual space in various planes -semantic, formal, and ideological. Therefore, we consider that studying his writing allows us to contribute to the considerations about the multiple ways of sense production created in the dialog between artistic languages, in this case, between music and literature.
\end{abstract}


CATEDRAL Tomada: Revista de crítica literaria latinoamericana / Journal of Latin American Literary Criticism Pensar con sonidos. Los universos musicales en El Trino del Diablo de Daniel Moyano.

In this paper, we do a reading of El trino del diablo* in order to show the ways in which the narrative universe of the novel takes shape by means of the incorporation of myths and conceptions about music and interpreters, influencing the construction of areas of membership and cultural and identity frames of reference. Likewise, reading taking into consideration the textualization of practices, values, and musical references is a possible way of knowing and understanding the political and social world of the 1970s in Argentina.

Keywords

Music, literature, identity, power.

\section{I}

El trino del diablo, novela cuyo título remite a una sonata para violín y clave compuesta en 1765 por el compositor italiano Giussepe Tartini, cuenta con dos versiones escritas por Daniel Moyano. La primera de ellas, publicada en 1974 y, la segunda, en 1988, bajo el título El trino del diablo y otras modulaciones, edición que incluye además seis relatos.

En toda la producción literaria del escritor argentino la música ocupa un lugar predominante. Su universo narrativo se construye a través de una trama intertextual que incorpora mitos y concepciones sobre la música, discursos y voces cuyo funcionamiento en la escritura no sólo es anecdótico sino la clave constructiva y compositiva de personajes, situaciones y conflictos, generando un espacio textual complejo. Este aspecto peculiar de su narrativa, crucial para comprender su obra, ha sido considerado en distintos estudios críticos (Gil Amate 1993; Corona Martínez 2005; López 2012). El objetivo de este trabajo es colaborar en esa línea de análisis a partir de una lectura de la novela El trino del diablo, mostrando las formas en que la escritura literaria textualiza mitos y concepciones acerca de la música que inciden en la construcción de espacios de pertenencia y marcos de referencia cultural e identitaria.

Siguiendo la propuesta de M. Bajtín, comprendemos el funcionamiento interdiscursivo entre literatura y música desde la concepción de dialogismo, en cuyo marco podemos pensar las relaciones intertextuales y la producción de sentido a través de fronteras discursivas permeables (Bajtín 1989; Barei 1991). Desde esa perspectiva también interpretamos la relación entre las dos ediciones de la novela, 
considerando la última como el producto de un trabajo de reescritura que establece una relación dialógica e intertextual con su primera versión. Como sostiene G. Balestrino (1997), una reescritura funciona a modo especular refractando a su modelo, estableciendo cercanías y distancias con el mismo, reelaboraciones y transformaciones que pueden alcanzar distintos grados de intensidad; en este caso, las trasformaciones devienen particularmente de una situación enunciativa diferente: mientras la primera fue escrita previamente al golpe de Estado ocurrido en 1976 en Argentina y al exilio del escritor en España, la segunda, reescrita desde el exilio en Madrid, resignifica esa traumática experiencia histórica.

El recorrido de lectura inicia con el análisis de las concepciones sobre la música presentes en la novela mediante la textualización de mitos en torno a su poder y a la función del músico, para luego avanzar hacia la construcción de espacios, en los que también inciden las referencias a ritmos y sonidos, ya sea en la configuración del espacio interior y de la subjetividad del protagonista, ya se trate de los espacios sociales del margen urbano o de un espacio estético alternativo. A lo largo de la novela se entrecruzan diversas líneas en torno a la concepción de la música, como el poder mágico del sonido de raíz mítica, la idea de una "música de las esferas", de procedencia mística y metafísica o la consideración de los efectos fisiológicos del sonido, ya sean éstos nocivos o beneficiosos y curativos. Todo este sistema de pensamiento en torno al arte y la música forma parte de una matriz cultural muy antigua, presente ya desde las formulaciones de los pitagóricos y Platón en la Antigua Grecia, reformulándose en el Medioevo con pensadores cristianos como Boecio y, posteriormente, con filósofos modernos como Kepler, y que podemos encontrar materializado en textos literarios como la novela que analizamos. ${ }^{1}$

Todas estas referencias musicales juegan un rol muy importante en la trama y el sentido de la novela, relacionadas con el contexto político e ideológico del momento de producción, dando cuenta de una complejidad sociocultural atravesada

1 Tales referencias se encuentran no sólo en esta novela sino en toda la producción de Daniel Moyano. Ver López 2012 y Corona Martínez 2005. 
por relaciones de poder, imposiciones, jerarquías, antinomias y tensiones irresolubles. Se configura así un espacio polifónico, una trama de voces y discursos que inscriben en el texto diferentes horizontes socio-ideológicos en el que se expresan diversas posiciones no sólo en torno a las concepciones sobre el arte y la música sino también a la historia nacional, a las complejas y conflictivas relaciones entre la capital del país y las provincias del interior, a las situaciones de desigualdad y marginalidad social, presentes en el convulsionado contexto político, social e ideológico de la Argentina en los años 1970. Dada esta complejidad textual, el efecto de lectura de la novela es igualmente fragmentario y sorpresivo ante el despliegue de un mosaico de realidades simultáneas que, a la manera de un caleidoscopio, refracta una trama abierta e infinita de piezas, voces y miradas.

\section{Ambivalencias. En torno al poder del sonido}

En Introducción a la filosofía de la música, Lewis Rowell (1996) afirma que en la Grecia Antigua:

La música era considerada como algo valioso y desconfiable a la vez: valioso por su capacidad de despertar, complacer y regular el alma y de producir buenas cualidades en sus oyentes; pero, a la vez, se desconfiaba de ella por su capacidad de sobre-estimular, drogar, distraer y llevar a excesos en la conducta. Parte de esa actitud ambivalente ha persistido a lo largo de la historia de la civilización occidental y es aún hoy evidente. (47)

Esta concepción resuena en la escritura de Daniel Moyano que, mediante la textualización de mitos y concepciones en torno al poder mágico del sonido y sus efectos en los oyentes, va configurando un espacio ambiguo y fluctuante en la valoración del arte musical. 
La primera pista de lectura en esta línea se encuentra en el título de la novela, tomado de una conocida sonata para violín y clave compuesta por Giuseppe Tartini (1692-1770). ${ }^{2}$ Valorada como una obra compleja que exige un gran virtuosismo, en torno a su composición gira una leyenda alimentada por su mismo autor. Según la misma, el origen de la sonata fue producto de un sueño en el que el compositor realizaba un pacto con el diablo. ${ }^{3}$ A partir de esta leyenda el título adquiere una densidad polisémica fundada en una valoración ambivalente en torno a la música y su origen: el poder de la música y su procedencia, en este caso sobrenatural y asociada a lo demoníaco, y el efecto de placer, éxtasis y goce estético que provoca en los oyentes. "Trino"4 y "diablo" connotan al mismo tiempo cielo e infierno, ambivalencia en la que se enmarca igualmente la figura del protagonista, Triclinio, a quien se asocia con diversas figuras vinculadas al poder mágico del Sonido: ya sea el mito del cantante frigio Orfeo, ${ }^{5}$ el violinista romántico Nicolo Paganini, ${ }^{6}$ o el personaje del relato "El flautista de Hamelin". La conexión entre ellos reside en la posesión de un don sobrenatural, un virtuosismo tan grandioso que su procedencia sólo puede explicarse en función de fuerzas mágicas, en el contexto de la mitología griega, o demoníacas según la concepción cristiana medieval. Rowell explica al respecto, que lo demoníaco ocupa un lugar destacado en los mitos en torno al poder del sonido:

\footnotetext{
${ }^{2}$ Violinista, compositor y teórico italiano del período Barroco. Fue reconocido como uno de los mayores virtuosos del violín de su época. La sonata para violín con acompañamiento de clave en sol menor, conocida como "Trino del diablo", fue compuesta en 1765 (Downs 48).

${ }^{3}$ Se trata de una leyenda acerca de la composición de esta sonata que fue recogida por Jérôme Lalande en su libro Voyage d'un François en Italie. Una referencia a la misma se puede consultar en Fisas (171).

${ }^{4}$ En el lenguaje musical se denomina "trino" a un ornamento que consiste en una rápida alternancia entre dos sonidos a distancia de semitono. Ver Diccionario Oxford de la Música (2008).

${ }^{5}$ Señala Rowell que este mito griego "proporciona la imagen mítica más familiar del músico" y que Virgilio menciona la versión más familiar de la historia de Orfeo en el cuarto libro de Geórgicas. También afirma que tiene características comunes con mitos de la fertilidad del Cercano Oriente (69).

${ }^{6}$ Violinista y compositor, reconocido como el modelo del intérprete virtuoso del siglo XIX. Vivió entre 1770 y 1825 (Llinás 36).
} 
CATEDRal Tomada: Revista de crítica literaria latinoamericana / Journal of Latin American Literary Criticism Pensar con sonidos. Los universos musicales en El Trino del Diablo de Daniel Moyano.

La Iglesia medieval sospechaba mucho de la música y jamás logró eliminar la superstición de que los poderes de un músico provenían del diablo y que se los podía usar para incitar al fiel al pecado. [...] Lorelei y el Flautista de Hamelin son prolongaciones directas de la suspicacia popular de que la música constituía una trampa. Se puede demostrar que el culto al virtuoso se desarrolló a partir de esta interpretación del mito órfico: Nicolo Paganini y Franz Liszt semejaban la reencarnación de Orfeo en el mundo del siglo XIX, dotados de una habilidad sobrehumana que seguramente provenía del diablo. (73)

En la novela esa matriz de sentido articula otras líneas y funciona como una caja de resonancia en la configuración de campos de sentido, recreándose, incorporando nuevos significados y operando a modo de círculos concéntricos. La música adquiere un sentido ambivalente entre el reconocimiento de su poder mágico y la sospecha ante el misterio de su fuerza y seducción; entre su asociación a lo celestial o a lo demoníaco o, en la concepción clásica de la antigüedad, entre cosmos y caos. En esta ambivalencia se funda la mayor parte de la novela, lo cual puede constatarse en distintos órdenes: en el origen mágico que se atribuye a la música y a una obra de arte en general -origen que los griegos atribuyeron a las "Musas" y los románticos llamaron "inspiración"; en los efectos fisiológicos de la música en los oyentes, creencias comunes a muchas culturas y de particular desarrollo en la filosofía griega; en el rol que se atribuye al arte musical en una sociedad y en las miradas contradictorias respecto de la figura del artista (Rowell 1996; Fubini 2004).

El poder de la música para vencer a la naturaleza y conseguir aquello para lo cual las palabras resultan insuficientes, constituye el núcleo del mito de Orfeo. ${ }^{7}$ Según el mismo, Orfeo poseía el don de encantar a través del sonido, dominando la

${ }^{7}$ Uno de los mitos de mayor incidencia en la cultura musical de Occidente, retomado por la literatura, la música y el teatro. La primera ópera, compuesta por Monteverdi y estrenada en Florencia en 1607, lleva por título Orfeo (Llinás 21). 
naturaleza, domesticando a las fieras, e, inclusive, logrando hazañas imposibles para los mortales: cruzar el Hades y convencer a Caronte y Plutón para rescatar a su amada Eurídice de la muerte. Este mito es crucial en la representación del músico y, por extensión, del artista. Entre lo diabólico, lo divino y lo sobrenatural, en la novela tal representación entrama una constelación de figuras: Orfeo, el mítico cantante frigio; Paganini, el virtuoso violinista romántico; y, por último, el enigmático protagonista del cuento popular "El flautista de Hamelin". En la novela, de la misma manera en que Orfeo domestica a la naturaleza y vence a la muerte a través de su lira, el padre San Francisco Solano domestica almas mediante su violín y el maestro Spumarola gana adeptos políticos gracias a la enseñanza musical. Triclinio, por su parte, al igual que el flautista de Hamelin, se deshace mediante la música de una "procesión de ratas" y de "torturadores" junto a sus "instrumentos de tortura".

En estas asociaciones se condensa la concepción en torno al poder del sonido y de la música, sus efectos mágicos y del músico en la sociedad, fluctuante entre la confianza/desconfianza; lo celestial/lo diabólico; lo humano/lo divino y lo transcendental. La figura de Triclinio se construye en ese juego ambivalente. Abstraído en su propio universo sonoro, no puede ver y comprender su entorno ni tampoco se preocupa por ello. Los sonidos constituyen su lenguaje, su modo de pensamiento, su refugio, su "mecanismo de defensa" y su único reducto de libertad. Según la perspectiva desde la cual sea observado, puede presentarse como soñador e ingenuo, inmerso en su propio mundo o bien, desde otras miradas, convertirse en objeto de sospechas por su actividad artística y ser considerado peligroso e incluso "subversivo". Asimismo es mirado como un personaje exótico, famoso en su ciudad, e incluido en las "visitas folclóricas que con un guía al frente hacían en invierno los turistas porteños" (Moyano, El trino 18).

En el imaginario sobre la música reproducido por las revistas que llegan desde Buenos Aires a La Rioja, puede advertirse también una concepción ligada al encantador poder sugestivo del sonido, pero en este caso a través del mito del artista romántico, el virtuoso violinista Paganini, junto a un mundo de fama, dinero, éxito, 
CATEDRAL Tomada: Revista de crítica literaria latinoamericana / Journal of Latin American Literary Criticism Pensar con sonidos. Los universos musicales en El Trino del Diablo de Daniel Moyano.

mujeres y viajes por Europa. La reproducción de ese imaginario alimentado por las revistas que llegaban al pueblo desde Buenos Aires, se localiza en una realidad absolutamente distinta y distante a la que presentan dichas publicaciones. Para el padre de Triclinio, ilusionado por esas lecturas e influenciado por el discurso exitista que rodea a la leyenda de Paganini, la música también puede operar milagros; en este caso, sacar a Triclinio de la pobreza:

Entre las revistas venidas de Buenos Aires hubo una que revoloteó por la imaginación del viejo. Hablaba de Paganini, un violinista que después de inventar el violín lo llenó de monedas de oro y compartió el lecho de una hermana de Napoleón. No estaba mal. Triclinio era tan flaco como los dibujos que representaban al diabólico instrumentista, incluso se le parecía. Además, si tocar el violín era tan difícil como allí se decía, el que lograra poseer su técnica sería muy bien pagado. (Moyano, El trino 13)

También en este caso subyacen leyendas en torno a la música y al músico en las que predomina la idea del poder mágico del sonido. El virtuosismo se explica como un don sobrenatural y los efectos de encantamiento se producen por ese despliegue de maestría técnica.

Los efectos que ejerce la música sobre sus receptores es otro de los grandes temas y preocupaciones relacionados con la concepción mágica del sonido. En efecto, entre los poderes atribuidos a la música desde la antigüedad se consideraba que ésta podía incitar a la calma o a la acción; dirigirse al intelecto o desatar la pasión; promover un estado de mesura o desmesura; producir efectos benéficos o nocivos; equilibrio o desequilibrio (Rowell 1996). Determinados ritmos y melodías podían conducir a un desborde, a la desmesura, la alteración de los sentidos y de las conductas o la locura, atribuyendo también al sonido un efecto embriagador similar al que produce el vino. En la antigüedad clásica esa ambivalencia se expresa en la antinomia entre lo apolíneo y lo dionisíaco; en la tradición cristiana, por su parte, se explicará en términos de "celestial" o "diabólico". 
Las influencias que ciertos tipos de música ejercen sobre sus oyentes puede ser positiva, y brindar equilibrio al alma o, todo lo contrario, provocar nocivos efectos. Para "los torturadores" de los cuales Triclinio se deshace, la música ejerce una influencia a la vez "mágica" y "diabólica", ya que los lleva al suicidio. Al mismo tiempo, funciona como elemento liberador puesto que permite a la sociedad “expurgar” y "exorcizar" sus males. En ambos casos, de todas maneras, la música posee poderosos efectos.

El pensamiento acerca del poder transformador y liberador de la música también opera en la construcción del espacio de Villa Violín. Allí sus habitantes, identificados como "artríticos", abogan por una transformación política y social denunciando a través de sus prácticas y partituras no convencionales aquellas cuestiones que anhelan cambiar. Esta triple acción de la música tiene connotaciones religiosas, políticas, y también "liberadoras" de un estado particular de descontento y opresión. En todo caso, lo que destacan es el poder de transformación posible a través de ella. ${ }^{8}$ De esta manera la música se convierte en un poderoso instrumento de poder, o de "contra-poder", ya que es a través de su función tanto de "encantamiento" como de "exorcismo" que logra hacer frente al poder y a los discursos hegemónicos, operando en tal caso como alternativa contrahegemónica. ${ }^{9}$

La práctica musical es igualmente objeto de una doble valoración, ya que si bien la figura del músico se rodea de misterio, poder, seducción y virtuosismo, también es mirado con sospecha y asociado a una debilidad de carácter. Se trata igualmente de una imagen convencional de la figura del músico y, por extensión la del artista, que lo presenta como un ser aislado, incomprendido y débil, representación en la cual resuenan también ecos del mito de Orfeo. Éste demuestra debilidad y falta de voluntad cuando no puede evitar mirar a Eurídice y, de esa manera, la condena para siempre al Hades, frustrando su rescate. La culpa y el

\footnotetext{
${ }^{8}$ Contraria a una de las concepciones más arraigadas socialmente sobre la música como adorno y pasatiempo.

${ }^{9}$ Cecilia Corona Martínez (2005) destaca cómo en la narrativa de Daniel Moyano la música se configura como contradiscurso.
} 
arrepentimiento por esta acción conducen a Orfeo a aislarse del mundo social, sumido en la tristeza. Así, la representación del artista se construye en el doble juego de destacar su poder y su debilidad o falta de carácter.

Se configuran de tal manera dos posturas extremas: el poder invencible de la música frente a, paradójicamente, la debilidad del músico. Sin embargo, la novela no resalta una condición inherente a la personalidad del músico, sino que más bien destaca la impotencia del artista en una sociedad que no valora su arte, o bien que coarta sus posibilidades de crecimiento y desarrollo creativo. Esto es lo que ocurre con la condición de Triclinio, a quien se le considera "desubicado", "desarraigado", “exiliado", "exótico" y, en todos los casos, improductivo. Igualmente ocurre con las imposiciones a la producción musical según las regiones geográficas, situación que se encuentra exagerada hasta el absurdo. Triclinio, por su procedencia regional, sólo puede tocar folclore:

El director de cultura, un hombre especializado en todas las artes, a quien Triclinio pidió ayuda, le leyó el decreto de recuperación del patrimonio nacional cultural argentino. Según el mismo, era imposible conseguir para el muchacho una ubicación en el departamento de música, salvo que supiera tocar el bombo o el charango. Según el decreto, La Rioja debía aportar solamente folclore a la música, reservando para Buenos Aires, en su carácter de cosmópoli, el usufructo de otras variedades musicales. ( $E l$ trino 29)

Por lo tanto, la "debilidad" no se muestra como un atributo inherente a un tipo de carácter especial constitutivo de la condición de artista, sino que se enfatiza y muestra un tipo de funcionamiento del poder y de conflictividad social que, a través de los discursos dominantes, actúan como reguladores y evaluadores de los comportamientos sociales. 


\section{Música de las esferas y armonía universal. En búsqueda de la unidad primigenia.}

Otro de los intertextos significativos en la novela es el de la concepción de una música y armonía universales, procedente de la mitología y la filosofía antiguas, siendo luego reelaborada por la tradición cristiana y por la filosofía moderna. Esta concepción se encuentra textualizada en toda la obra de Daniel Moyano, quien conocía estas teorías y se mostraba interesado en ellas; así, citando a Kepler, Daniel Moyano daba cuenta de este pensamiento:

El decía, por ejemplo, que la tierra al desplazarse producía un sonido, una música en el espacio. Pero que esa música no se la podía oír con los oídos, sino con el intelecto. Y que esta música nuestra es sólo una interpretación de esa otra que no podemos oír. Sólo Dios puede oírla, decía. (Giglio 78)

La idea es simple y compleja a la vez: parte de la especulación en torno al movimiento y rotación de los planetas, los cuales como cuerpos en el espacio producían sonidos que, se creía, estaban a distancias equivalentes a las cifras representadas por los intervalos musicales. En esa emisión de sonidos a diferentes alturas, los cuerpos celestes guardaban una relación armónica entre sí a la vez que configuraban una música del universo, superior a la música terrenal y sólo posible de ser captada por la razón o por el intelecto.

En la concepción pitagórica, el concepto de "armonía” está relacionado con las matemáticas y constituye una clave de interpretación del universo, puesto que desde esa perspectiva "todo el cielo era una escala musical y un número" (Rowell 50). La armonía existe en el universo contraponiendo caos/cosmos como un equilibrio y una unión de contrarios. Al mismo tiempo, esa concepción de armonía se expresaría en una conexión entre el orden universal, el orden social y el equilibrio 
CATEDRAL TomadA: Revista de crítica literaria latinoamericana / Journal of Latin American Literary Criticism Pensar con sonidos. Los universos musicales en El Trino del Diablo de Daniel Moyano.

interno de cada ciudadano. Lewis Rowell afirma que en el pensamiento griego la armonía

[...] era un símbolo del orden universal, la unión de todos los elementos del cosmos: los cuatro elementos básicos (tierra, agua, fuego, aire), las formas más elevadas de vida (el hombre) y la estructura del universo (los planetas, el sol y la luna) [...] A este concepto le debemos la idea de microcosmos y macrocosmos: el hombre, el "pequeño universo" o microcosmos, contiene el mismo complejo de elementos y relaciones que el universo mayor mismo, el macrocosmos, y su naturaleza está regida por los mismos principios y proporciones. (50)

La concordancia entre música, libertad y vida política y social, implica un equilibrio tenso y un juego de opuestos. En la medida en que ese equilibrio se vea alterado acontecen discordancias, se alteran las relaciones sociales y con ellas la música y la libertad. El mundo construido en la novela dista de ser "armónico" desde este punto de vista; por el contrario, gobierna el caos y el desequilibrio, la irracionalidad y la desmesura. Por ello, esta concepción de la armonía universal opera como trasfondo de un paraíso perdido, como una constante y trabajosa búsqueda de un estado utópico, de una unidad primigenia entre hombre, naturaleza, cosmos y divinidad.

En la novela se construyen numerosas tensiones entre diferentes tipos de ataduras e imposiciones que coartan el ejercicio pleno de la libertad en una realidad social en la que imperan situaciones como la censura, la tortura, el exilio, y la desconfianza entre los ciudadanos. Se presenta así una sociedad en permanente desequilibrio, generadora de desigualdades que son en gran parte producto de intercambios económicos asimétricos en distintas escalas: entre la metrópoli y sus colonias en el primer capítulo; entre la capital del país y las provincias del interior, relación que se traduce en términos de riqueza/ pobreza; entre las prácticas 
musicales del centro, concentradas en el Teatro Colón, y las de la periferia, simbolizadas en Villa Violín.

La desigualdad y las relaciones asimétricas entre la capital del país y las provincias del interior reproducen situaciones de colonialidad. De esa manera, se comprende la ironía en la descripción del tipo de intercambio generado entre el padre de Triclinio y Buenos Aires, ya que "A cambio de miel el viejo recibía en pago grandes cantidades de revistas ilustradas, con hermosas historietas y tapas de color." (El trino 12).

El intercambio económico desigual implica también desequilibrios culturales y una distribución geopolítica de la producción musical, según la cual el interior del país provee de folklore mientras que la capital puede desarrollar otras vertientes. Así, las relaciones jerárquicas y tensiones entre centros y periferias se manifiesta en políticas culturales que regulan la producción artística y definen desde un centro- el tipo de expresión adecuada para las provincias: folklore, telurismo, regionalismo. En la novela se expresa una postura sumamente crítica frente a ésta y otras divisiones jerárquicas, tales como la distinción entre música clásica y popular, entre arte convencional y vanguardista, entre cultura regional y cosmopolita.

Hay un lugar, sin embargo, en el cual más allá de las carencias y la marginación social, la música llega a significar un reducto de libertad y puesta en práctica de una forma de armonía. Para los habitantes de Villa Violín, ese espacio de la periferia, orilla y margen de la ciudad, receptáculo de exiliados y marginados, la música era

Una forma de transición, como un código o constitución que todos amaban igualmente, es decir ninguno más que otro como para no entorpecer sus sentidos con ella. Habían encontrado un equilibrio... que pasaba inadvertido como la libertad que gozaban. (El trino 60) 
No obstante, esta concepción sobre la concordancia entre cosmos, estado, individuo y el lugar preponderante de la música en la formación del ciudadano y del orden social, puede albergar en su seno ideas, acciones y prácticas tendientes a la regulación y el control. Por un lado, debido a las sospechas que generan los efectos de la música en los oyentes; por otro, en tanto, suponen la postulación de una forma de gobierno y de los comportamientos que se consideran adecuados de acuerdo a un determinado orden social. Como veremos a continuación, en El trino del diablo las situaciones de imposición, prescripción, regulación y control sobre la música que se practica y que se escucha, son acabadamente descriptas y cuestionadas.

\section{Arte y Estado. Políticas de la producción y de la escucha.}

La ambivalencia en torno a la valoración de la música según el rol que se le atribuye en la sociedad y en la formación del ciudadano, se traduce en políticas estatales de regulación y control sobre lo que se produce y lo que se escucha. Como venimos mostrando, la tradición de pensamiento de vertiente platónica y pitagórica, postulaba una función importante de la música en la educación, ya que se consideraba que reunía la capacidad para moldear los caracteres, influir en las conductas e incidir en las emociones. Por tal motivo, los mecanismos de control sobre ella se orientaban a prescribir que no toda música podía ser considerada "buena” para la formación del carácter y la educación de los jóvenes.

Particularmente para Platón, la formación del ciudadano ideal en un Estado ideal debía contemplar el estudio y ejercicio de la música, pero no de cualquier tipo. Por ello, distinguía entre una música de carácter "racional", dirigida al intelecto, y una música de origen "irracional”. Tan sólo la música destinada al intelecto debía ocupar un lugar relevante en la sociedad. Desde tal perspectiva, también quienes se dedicaban a la música debían hacer uso racional de ese don: 
También la música, en tanto emplea sonido audible fue concedida por la armonía. Y la armonía, que tiene movimientos emparentados con las revoluciones del alma interna a nosotros, le es dada por las Musas al que hace uso inteligente de ellas, no como ayuda para el placer irracional (como se supone en la actualidad) sino como auxiliar para la revolución interna del alma, cuando ésta ha perdido su armonía, para ayudarle a que la restaure y ordene y esté en concordancia consigo misma. (Platón, cit. en Rowell 46)

En dicha concepción se expresa una antinomia entre dos tendencias opuestas, lo apolíneo y lo dionisíaco, representada en las figuras de Apolo y Dionisio. Bajo los efectos de la música y la embriaguez de los sonidos, los cuerpos pueden liberarse y desoír la voz de la razón, del intelecto. Esta ambivalencia conduce a sospechas pero sobre todo a un esfuerzo por su control y regulación, en tanto afecta directamente el comportamiento de los ciudadanos y, por lo tanto, el orden social. También, como vimos antes, se entabla una lucha entre debilidad/poder relacionada con la formación del carácter del ciudadano a través de la música, ya que se consideraba que ésta promovía, según los ritmos, melodías, tonos, e instrumentos utilizados, determinadas virtudes: equilibrio, valentía, raciocinio, o bien desmesura, dejadez, embriaguez:

La idea del carácter conllevaba importantes implicancias políticas, ya que tanto Damón como Platón creían que la música podía implantar todas las virtudes (valor, moderación, e inclusive justicia) en el carácter humano, es explicable que Platón abogara por la música como continuación de la política estatal. Sostenía que la música formaba el carácter no sólo del ciudadano individual sino también del Estado como totalidad; la música podía, en efecto, apoyar o subvertir el orden social establecido, pues (como dice Platón en La República) "Cuando cambian los modos de la música, 
CATEDRAL Tomada: Revista de crítica literaria latinoamericana / Journal of Latin American Literary Criticism Pensar con sonidos. Los universos musicales en El Trino del Diablo de Daniel Moyano.

las leyes fundamentales del Estado siempre cambian con ellos." (Rowell 59)

En el Trino del diablo la desconfianza ante la música y sus efectos provoca formas de control generadas desde el Estado que conducen, en casos extremos como los que textualiza la novela, de la sospecha a la prohibición y de ésta a la tortura, al destierro, la marginalidad o al exilio. La relación entre música y política es una línea de sentido transversal que también se construye en una oscilación y ambivalencia, en el doble juego entre sometimiento y liberación. Por su potencialidad, la música puede ser usada tanto para controlar, someter, regular como también puede convertirse en un mecanismo de liberación, ejercicio de libertad y consecución de equilibrio.

La referencia al rol de la música durante la conquista muestra cómo ésta puede utilizarse como un recurso fundamental para el control social. Al núcleo de sentido presente en el mito de Orfeo, es decir la potencialidad seductora del sonido para calmar, aquietar, encantar y domesticar, se superpone, en la novela, la capacidad de controlar y sofocar la rebelión social. Así, se explica que San Francisco Solano “....llegó desde España para evangelizar a los indios mediante el sencillo procedimiento de tocarles el violín cada vez que éstos decidían rebelarse contra la autoridad española" (El trino 10).

De la misma manera, apelando a la ayuda de la música, procede el maestro de violín Spumarola, quien además de músico es representante de un partido político y recurre al encantador sonido del violín para ganar adeptos: “Atraídas por el violín -un Steiner legítimo- llegaron allí muchas personas que luego terminaron afiliándose al partido, de modo que más valió a Spumarola su violín que su prédica..." (El trino 15).

Como señalamos antes, la novela textualiza cómo la sospecha ante el poder de la música puede derivar en situaciones de intolerancia, censura y persecución. Los cambios políticos e ideológicos ocasionan concepciones también divergentes en cuanto a la actividad musical. De tal manera, la proscripción de la actividad 
política - por los golpes de Estado que implican la interrupción de la vida institucional y de la democracia- provoca la interrupción de la actividad musical:

[...] el gobierno nacional tuvo que prohibir más tarde la enseñanza del violín en aquella antigua provincia, de acuerdo con lo sugerido en un ensayo por el general Schönpferd, donde éste sostenía que tantos violinistas formaban un verdadero ejército y, que en caso de que esa gente, en vez de música, escogiera el camino de la subversión, no habría suficiente capacidad operativa para contenerla. Ilustraba la nota una fotografía donde unos diez mil violinistas marchaban sobre Buenos Aires, pero en vez de sostener los estuches de sus violines con una mano, colgando al costado, los empuñaban como ametralladoras. El título de la nota, bastante capcioso para las pacíficas intenciones de los músicos riojanos, decía: “¿Violinistas o guerrilleros?”. (El trino 16-17)

Spumarola es declarado "apóstata por la UCR", además de "conspirador, intelectual y persona no grata" (18). Una vez caída la actividad musical bajo un manto de sospecha, aparecen "las comisiones investigadoras" afirmando que "Spumarola con sus violinistas estaban creando la violencia en la provincia" (18).

Esta situación de sospecha y persecución continúa cuando el protagonista se radica en Buenos Aires, y el encargado de la pensión donde reside Triclinio, un ex-violinista, resulta ser un "delator", un espía a sueldo que reconoce que el gobierno "pasa unos mangos cuando descubro a falsos violinistas que dentro del estuche en vez de violín llevan armas. Usted sabe cómo andan las cosas” (39).

La música actúa entonces, ya sea como una actividad susceptible de sospechas, potencialmente peligrosa, ya sea como un mecanismo de defensa ante la realidad, como sucede para Triclinio, para quien los sonidos constituyen una posible vía de escape. El capítulo 4 de la primera versión, "De cómo se salvó Triclinio, gracias a los sonidos", destaca esa posible salvación por la música ante 
CATEDRAL Tomada: Revista de crítica literaria latinoamericana / Journal of Latin American Literary Criticism Pensar con sonidos. Los universos musicales en El Trino del Diablo de Daniel Moyano.

situaciones que escapan a una lógica racional, que resultan inverosímiles, incomprensibles y ante las cuales se ofrecen explicaciones que rondan entre lo mágico y lo fantástico:

Al ver la inutilidad de los mecanismos de defensa para protegerse de las calamidades, la gente recurrió a los amuletos traídos de una fábrica de Avellaneda, pero los amuletos mismos contrajeron las enfermedades endémicas [...] Submarinos capaces de perforar la tierra vinieron desde el Pacífico por debajo del territorio y se bebieron el agua de las vertientes subterráneas, mientras las viejas y los niños salían en procesión con el Santo en andas pidiendo que lloviese. [...] mientras eso sucedía, Triclinio, sin poder entender lo que pasaba a causa de los sonidos, aprendió 195 nuevos golpes de arco. (El trino 20-21)

A esos extraordinarios sucesos se suma una ola de prohibiciones de distinto alcance, desde el uso de los medios de transporte, la actividad musical, la divulgación de las noticias, al tiempo que la provincia se convertía en un gran circo: "Todo aquél que deseara enterarse de lo que en la provincia sucedía, debía pagar entrada además de un módico impuesto que era girado a Buenos Aires para pagar el derecho a integrar el territorio nacional." (23). En esa ola de prohibiciones entra también la música, con lo cual Triclinio pierde su fuente de ingresos:

Le informaron entonces que las serenatas habían sido declaradas inmorales por el gobierno, y que en consecuencia estaban prohibidas. Otros le dijeron que el señor Interventor hubiera pasado por alto la cuota de erotismo que puede tener una serenata, pero decidió prohibirlas definitivamente cuando varios presos, entre ellos un obispo, se fugaron de la cárcel donde esperaban un dictamen del fuero antisubversivo, durante la ejecución, 
precisamente, de una serenata, que al parecer era una forma cifrada de comunicación, según informes suministrados por la CIA. (El trino 26)

En Buenos Aires, por su parte, resurgían

[...] los instrumentos de tortura quemados en 1813, y para salvar al país resolvían, mediante un decreto de lujo, prohibir la miseria, el hambre, las enfermedades endémicas, la mortalidad infantil, las carestía de la vida, las protestas y el deseo de reproducirse. (El trino 23-24)

En ese contexto, se menciona también la "misteriosa" desaparición de personas:

[...] los que no podían evadirse físicamente lo hacían por vía metafísica, y aún en las formas más misteriosas, como los violinistas de Spumarola, que desaparecieron del territorio con sus violines y aún son buscados en todo el país ante el temor justificado de una reacción en cadena por parte de estos instrumentistas famélicos desparramados por todas las provincias. (El trino 20)

El aparente tono de ingenuidad con el que se enuncia el "misterio" en torno al paradero de los violinistas, crea en realidad el efecto de elevar a un primer plano la persecución, la censura y la desaparición de personas. En este fragmento, como ocurre en muchos otros, resuenan dos voces. A veces en forma más explícita, otras en forma más velada, se enuncian desde una mirada ingenua situaciones aparentemente triviales en las que, mediante lexemas saturados ideológicamente, se inscribe otra voz, otra perspectiva que revierte el primer sentido -sin anularlo. Mediante el recurso de hablar sobre música, se esconde la denuncia de otras cuestiones, situaciones aparentemente de diferente tenor que quedan superpuestas: 
la proscripción de Spumarola y sus discípulos, lo que vale decir de la actividad política en un contexto en el que se encuentra interrumpido el ejercicio democrático en el país; la persecución y la desaparición de personas; el temor ante la "subversión"; la pobreza, la falta de trabajo y el hambre en las provincias del interior.

Son estas condiciones las que, superpuestas, provocan en el protagonista la necesidad de migrar hacia la capital del país: el terror, la persecución y la búsqueda de trabajo y mejores oportunidades. Acá reside uno de los cambios más significativos entre la primera versión de la novela, de 1974, y su reescritura en 1988. El cambio no sólo es perceptible en la titulación de los capítulos sino, fundamentalmente, en la secuencia de hechos que provocan la migración de Triclinio a Buenos Aires. En la primera versión, la pobreza, los golpes institucionales, las prohibiciones, la falta de oportunidades, conducen a los padres de Triclinio a la decisión de morir. Luego de esto, Triclinio es detenido y su domicilio allanado; ante ese hecho de violencia, que se suma a la falta de trabajo, el protagonista decide dejar su provincia para probar suerte en Buenos Aires. La segunda versión, en cambio, enfatiza la situación de persecución, violencia y la falta de garantías constitucionales para los ciudadanos. El capítulo cuatro, titulado "Borrado de los padres de Triclinio", narra la detención de Triclinio y el allanamiento de la vivienda familiar, siendo estos sucesos los que provocan la decisión de los padres a morir:

Conducido más tarde a la comisaría por no tener carnet de violinista ni poder pagar la multa correspondiente, tuvo que soportar que desarmasen su violín en busca de impresiones digitales.

Habiendo comprobado los policías que su instrumento nada tenía que ver con los denunciados por Schönpferd, fue puesto en libertad condicional una mañana triste, tras un mes de encierro, previo allanamiento de su domicilio y de su diario íntimo, cuyo contenido tuvo que explicar por estar redactado con notación musical. 
$[\ldots]$

Encontró toda la casa revuelta por la policía. Las abejas habían huido. Colchones despanzurrados, partituras rotas, atriles doblados. Sus recuerdos, que no eran muchos pero sí hermosos, habían sido sacados de la oscuridad protectora donde vivían y, expuestos a la luz, se velaron y desaparecieron.

Sus padres, atados y amordazados en la piecita del fondo, le comunicaron su decisión irreversible de morirse. "Sólo te estábamos esperando para despedirnos. Después de esto es imposible vivir." (El trino y otras modulaciones 31 )

En vez del énfasis en la pobreza presente en la primera versión, la reescritura ahonda en la violencia, el terror, el miedo. Ello se explica por los diferentes contextos de producción de ambas versiones: la segunda recupera, desde la distancia que marca el tiempo, toda la experiencia de persecución, tortura y exilio que marcaron al período de la última dictadura militar en Argentina entre 1976 y 1983 y que implicó el propio exilio del escritor. Esa experiencia de vida constituye una bisagra, ya que entre la primera y la segunda versión cambia la historia y cambia la mirada; si en 1974 Triclinio aún podía permanecer un tanto al margen de esa realidad, salvarse a través de los sonidos, conservar cierta ingenuidad, pureza, y mantener su mundo interior a salvo, en la segunda eso se torna imposible:

Violados los objetos, velados sus recuerdos, alteradas las partituras por las máquinas policiales, y con los padres desaparecidos, vio Triclinio que llegaba la hora de decirle adiós a todo eso. Advirtiendo que incluso sus pensamientos habían sido alcanzados por aquella violación de su pasado y de su casa, se apoyó en el atril destrozado, vertió una brevísima lágrima y juró que nunca más lloraría ni volvería a su casa natal, que a partir de ese momento, según lo iba viendo, pasaba a pertenecer a la policía, a 
CATEdRal Tomada: Revista de crítica literaria latinoamericana / Journal of Latin American Literary Criticism Pensar con sonidos. Los universos musicales en El Trino del Diablo de Daniel Moyano.

convertirse en una celda, en un arrabal de comisaría. (El trino y otras modulaciones 33-34)

Estas significativas diferencias entre una y otra versión de la novela, permiten comprender en qué medida se inscriben las marcas de tiempo y espacio, y su radical importancia en la construcción del sentido de un texto. ${ }^{10}$ En la versión de 1974, tal como observamos antes, el universo discursivo está poblado de lexemas que remiten explícitamente a discursos de amplia circulación en ese contexto de producción: "subversión", "guerrilla", "guerrilleros", "ejército", "prohibición”, “capacidad operativa”, además de la inscripción de la lógica de un enfrentamiento dicotómico amigo/enemigo. En la versión de 1988, reescrita desde la distancia espacial y temporal y desde el exilio, el lenguaje da cuenta de la violencia, y la selección lexemática prioriza vocablos como "violación”, "tristeza”, “despedida", “oscuridad", "destrucción".

\section{Cuerpo, sonido y territorios. Voces del exilio y la violencia}

Los espacios construidos en la novela, atravesados y constituidos por sonidos, se perciben según ritmos y sonoridades propias: la vida en las provincias, los ruidos y sonidos de la capital del país o aquellos que pueblan el espacio marginal de "Villa Violín". La ciudad, sus habitantes y actividades, se convierten en cuerpos sonoros, cuerpos que vibran, que emiten sonoridades ya sea en forma individual o conjunta.

Buenos Aires genera en el protagonista la percepción del contraste existente entre la ciudad capital, una "ciudad feliz", "un paraíso", "con tanta riqueza

\footnotetext{
${ }^{10}$ Mijaíl Bajtín entiende la conexión de relaciones temporales y espaciales asimiladas artísticamente en la literatura como cronotopo, término procedente de la teoría de la relatividad que en la propuesta bajtiniana se construye como una categoría de la forma y el contenido (237).
} 
concentrada" (El trino 37) frente a la realidad de pobreza de su provincia. En la segunda versión, Buenos Aires se caracteriza como "La ciudad de los violines", productora de una musicalidad propia:

Triclinio se entretuvo los primeros días en Buenos Aires recorriendo la ciudad rítmicamente. Había calles un tá ta, calles un ta tá, y hasta de zorcico, tá ta ta tá ta. Una verdadera maravilla. La ciudad se movía sin pausas, no había silencios ni compases de espera en su eterna partitura: era un moto perpetuo ${ }^{11}$ sin barras de conclusión. (El trino 45)

Por contraste, los sonidos de La Rioja conformaban "una especie de lamento", "un plañir tristísimo" (El trino 42-43), el plañir de la pobreza, de la falta de trabajo y del hambre; un espacio conformado por las voces de los vendedores ambulantes, de los niños y jóvenes sin oportunidades laborales, motivo que desencadena migraciones hacia la capital en búsqueda de un futuro promisorio:

La mayoría de los riojanos, que no tenían otra cosa que hacer que esperar el futuro no entrevisto, se inscribieron en el conservatorio y lograron formar con el tiempo la famosa escuela violinística riojana, que produjo un éxodo masivo de población al no existir en la provincia una orquesta para ubicarlos. (El trino 16)

El interior del país también está caracterizado por un tipo de música que acalla otras voces, como la de los folcloristas que, "por los altoparlantes de los clubes", difundían "la última forma adquirida por la pobreza provincial, bella en esos cantos, porque el paisaje siempre es lindo aunque los personajes que lo pueblan no piensan lo mismo.” (El trino 43). Así, esta música no sólo hace inaudibles otras

\footnotetext{
${ }^{11}$ En cursiva en el original.
} 
debido a su emisión por los altoparlantes oficiales, sino que también funciona como pantalla, como un velo que al exotizar al otro, estetizar el paisaje y a sus habitantes, invisibiliza el sufrimiento y la pobreza. Instigado por esa realidad, Triclinio afirma: "Yo pretendí hacer sonar algo más interesante que un pregón, un discurso, una guitarra chayera o un gallo." (El trino 43$).{ }^{12}$

Una vez pasado el deslumbramiento ante la gran urbe, se produce el desencanto y los sonidos se transforman en ruidos que provienen del caos de una ciudad donde el personaje siente su desarraigo. Buenos Aires se convierte entonces en un espacio caótico y disonante. La primera versión enfatiza el ruido, la cacofonía, la discordancia y la multiplicidad sonora del espacio:

[...] en el fondo del patiecito de la nueva pensión [...] repercutían todos los ruidos de la ciudad, las sirenas de los barcos, los gritos de las canchas de fútbol, las orquestas populares, el estallido de bombas de gases lacrimógenos, las cotizaciones del dólar y las declaraciones solemnes. ( $E l$ trino 42)

La segunda versión, en cambio, hace explícita la percepción de esa ciudad desde la tristeza y la soledad:

Una tarde gris de tango; una tristísima tarde con ojeras; una tarde de sollozantes violines verlenianos; una tarde como las últimas tardes de este mundo; una tarde que lo encerraba en el fondo del patiecito de la nueva

\footnotetext{
${ }^{12}$ Este fragmento corresponde en la novela a la carta que Triclinio escribe al "presidente bueno", destituido en el momento de su entrevista con el protagonista. Refiere al presidente radical, elegido democráticamente, Arturo Illia (gobernó entre 1963 y 1966), depuesto por un golpe de Estado que pone al mando del gobierno al General Juan Carlos Onganía. El texto no da referencias explícitas, sin embargo ofrece algunos indicios para inferir que se trata de Illia, como su referencia a que es un presidente constitucional y su procedencia de Cruz del Eje, localidad de la provincia de Córdoba, Argentina.
} 
pensión, donde percutían y repercutían las discusiones tabernarias, las sirenas de los barcos que se alejaban entre adioses, los gritos de los fanáticos en las canchas de fútbol, las orquestas estridentes y desafinadas, el estallido de las bombas de gases lacrimógenos, las violentas cotizaciones del dólar y las declaraciones papales; una tarde patentizada por la certeza de que nunca más regresaría a la tierra de sus padres, que de paso era también la suya, en que las calles de Buenos Aires antes musicales habían perdido su inocencia y eran un puro ruido sin sonido, Triclinio, haciendo un gran esfuerzo anímico, evitó el afloramiento de una lágrima inútil. (El trino y otras modulaciones 51)

Buenos Aires se configura, asimismo, como el espacio sonoro de la violencia. Ya vimos cómo el clima de sospechas imperante implicaba persecuciones, delaciones, arrestos y violaciones a la integridad física y psíquica de los ciudadanos. En la capital del país Triclinio experimenta múltiples formas de violencia, ya sea institucional, por una sucesión imprevisible de golpes de Estado, o bien a través de la tortura física y la marginalidad que sufren los habitantes de Villa Violín. Una escena elocuente de la violencia es el final del concurso en el que participa Triclinio, cuando el teniente que gana el certamen corta las cuerdas y rompe el arco de su violín advirtiendo "Así se toca en la presidencia de la Nación" (El trino 41). Pero la violencia no sólo es audible a través de ruidos, gritos, y sonidos, sino también a través del silencio cómplice. Los ruidos acallan los sonidosgritos de la represión y la tortura, soterrados y negados, que van escribiendo una partitura del terror; la música puede también, ocultar y acallar la tortura: la ejecución del Presidente de la sonata "Trino del diablo" acontece simultáneamente a la tortura de los seis violinistas -artríticos- amigos de Triclinio en el sótano "Eran los ruidos de las torturas que se hacen en el sótano." (El trino y otras modulaciones 113).

Los espacios íntimos y personales se configuran igualmente a través del sonido. Así, la música cumple un rol fundamental en la construcción de las 
subjetividades. También en esta dimensión se esboza un espacio ambiguo, ya que cumple una doble función: margina y aísla, al mismo tiempo que acoge y protege. Triclinio construye un mundo propio de sonidos, que funciona como salvación y resguardo pero también conduce a la soledad, al exilio interior y al aislamiento. La música para Triclinio es un lenguaje propio, un lugar de pertenencia y una forma de conocimiento que le permite comprender la compleja realidad social mediante el tamiz de los sonidos. Por ello cumple simultáneamente distintas funciones, de integración y de aislamiento, pero también como autoprotección y "mecanismo de defensa" frente a situaciones incomprensibles y dolorosas. En el exilio interior creado por los sonidos puede ser feliz y estar indiferente a la realidad social: "Se me llena la cabeza de sonidos, eso pasa; ahora tengo todo el sonido de la acequia, y esto me va a durar varios días". (El trino 14)

No sólo su cabeza "se llena de sonidos" sino que sus pensamientos, experiencias y sensaciones se traducen mediante sonidos, a través de la escritura de su diario íntimo mediante notación musical. Así, la música constituye para Triclinio un lenguaje propio que lo aísla del mundo y de los otros, operando como un exilio interior y constituyendo su principal modo de comunicación. Esta situación impide al personaje escuchar a los demás y comprender las palabras: éstas son percibidas por Triclinio como puro significante, carentes de significado, sonidos inarticulados y sin sentido, burdas repeticiones sin eficacia. A la vez la novela enfatiza la simulación y el artificio creado por las palabras, factibles de conducir a un engaño, como así también la distancia entre los discursos y los acontecimientos: "palabras rimbombantes que adornaban la historia y que no servían para nada." (El trino 49).

Ese mundo interior poblado de sonidos es precisamente la condición que impide a Triclinio advertir y comprender lo que ocurre a su alrededor:

¿De qué manera no te das cuenta?

-Se me llena la cabeza de sonidos. Esta es una enfermedad que llevo desde la infancia, desde que papá me hablaba de Paganini al lado de la acequia. 
Y esto a veces, cuando no hay sonidos, me desespera, porque yo también quisiera saber qué pasa. (El trino 103-104)

Esto se torna particularmente evidente en el Capítulo 16 titulado "Il trillo dil Diavolo" -en la primera versión- y 17 "El trino del diablo" -en la segunda-, cuando se produce el encuentro entre Triclinio y el presidente de facto, militar, padre de Ufa. Llevado por una primera impresión, Triclinio duda acerca de lo que se dice sobre ese presidente: Cuando estuvo cerca vio que el presidente tenía un rostro bondadoso, y pensó que todo lo que había oído y leído sobre las torturas, que llegaban hasta el Brasil, eran puras mentiras". (El trino 94)

Pero este fragmento es también una muestra de la ingenuidad con la cual a veces este personaje interpreta la realidad, y su imposibilidad de advertir lo que efectivamente ocurre en el país. La escena relatada da cuenta de una ambivalencia entre apariencia y realidad, lo visible y lo oculto, lo audible y lo inaudible, entre lo que ocurre en la sala y en el sótano:

-Eso es lo que dijeron los edecanes. Pero no era temblor. Eran los torturadores. Los mismos que dejaron artríticos a tus amigos de la villa. Porque esa artritis, aunque ellos lo oculten, no es por la humedad o la falta de ejercicio. Es por la picana eléctrica. Eran los torturadores los que hacían temblar el edificio desde abajo. (El trino 105)

Abstraído por los sonidos de la música ejecutada por el presidente precisamente, la sonata "Trino del diablo", Triclinio no puede descifrar los sonidos provenientes del sótano y la barbarie de lo que allí acontece. De modo que la música funciona para Triclinio simultáneamente como forma de exilio interior, de desconexión con la realidad y como sonido armonioso que tapa y oculta los ruidos del terror y la violencia. 
La novela pone en escena, de este modo, una diversidad de formas de experimentar el exilio. En primer lugar el microexilio formado por los sonidos que padece Triclinio. El mismo, que constituye un estado interior del personaje y sus formas de relacionarse con el mundo exterior y los otros, se entrecruza con condiciones sociales estructurales, como la marginación cultural, su condición de "cabecita negra" en la ciudad capital del país; su oficio de violinista en una provincia de folkloristas; la marginación política e ideológica de los habitantes de Villa Violín. Todos los espacios construidos en la novela se caracterizan en términos sonoros: las provincias del interior del país tienen un ritmo y sonidos propios, diferentes a los de la ciudad capital y, a su vez, también esta última alberga espacios que suenan a otro ritmo y con otros sonidos, como Villa Violín, margen y periferia urbana a la vez que alternativa y contradiscurso frente a la historia y el arte oficiales.

\section{Villa violín. Cultura oficial y margen estético}

Separada de la ciudad por un riachuelo, los contornos espaciales de la villa delinean la forma de un violín. El espacio, caótico en su apariencia, poblado no sólo por artistas exiliados sino también por "asistentes sociales", constituye un reducto de marginación dentro de la ciudad al que quedan condenados los desplazados del arte, de la historia, de la política y de la vida comunitaria, allí confinados por sospecha y apartados como "células peligrosas" en un régimen dictatorial. Sus habitantes son "arrojados" a ese espacio, llegan allí expulsados por el estado y la cultura oficial. Son mirados con sospecha por parte del poder, perseguidos, censurados, reprimidos y torturados, mojados con camiones hidrantes que los marcan con colores y los estigmatizan como diferentes, provocándoles daños a sus huesos y articulaciones: de allí su denominación como "artríticos". 
Exiliados del denominado "gran arte" y de los grandes escenarios, como el Teatro Colón, en Villa Violín se hace música no convencional, ejecutada con instrumentos fabricados con los materiales existentes y disponibles en la villa, y cuyas composiciones dan cuenta de una actitud rebelde que remite explícitamente al conflicto social, como el "Concierto para dos cámaras de auto y gases lacrimógenos". A pesar de la libertad gozada internamente en el espacio de la villa, sus acciones deben pasar inadvertidas y por ello los artistas actúan en clandestinidad, procurando escapar de la persecución y la tortura: "Lo que yo quiero, entendeme bien, no es prohibir sus juegos que vistos desde un nivel oficial pueden parecer peligrosos, sino evitar que los descubran y los fumiguen otra vez con esos horribles colorantes, que herrumbran sus artritis y sus casas" (El trino 78).

El espacio de ese exilio no elegido conjuga experimentación y libertad estética en un contexto adverso, marcado por persecuciones, torturas, y clandestinidad. Los músicos, sin embargo, exaltan su capacidad crítica y apuestan a la provocación de los cánones establecidos. Así lo expresan los seis violinistas artríticos ${ }^{13}$ con los que convive Triclinio:

Nuestra música, explicó uno de los seis, no es producto de la composición. Nosotros no componemos, en el sentido tradicional: simplemente hacemos sonar la música que está en la realidad. Por eso hemos tenido que recurrir a instrumentos diferentes.

Cualquier objeto se convertía en instrumento cuando había música en el ambiente: latas y botellas, trozos de manguera, repuestos viejos de automóviles, textos de revistas (utilizados en cantatas y madrigales),

\footnotetext{
${ }^{13}$ Esta referencia constituye un guiño que remite al conocido grupo de los seis en Francia, jóvenes compositores en el contexto de la posguerra europea de los años 20. Este grupo, conformado por Francis Poulenc (1899-1963), Georges Auric (1899-1983), Louis Durey (1888-1979), Arthur Honegger (1892-1955), Darius Milhaud (1892-1974) y Germaine Tailleferre (1892-1983), contó en sus inicios con la colaboración de Erik Satie (1866-1925) y las orientaciones estéticas de Jean Cocteau (1889-1963); el grupo exhibía una actitud desafiante y crítica ante los cánones musicales y artísticos imperantes, aunque mayormente se atenían a las formas clásicas heredadas.
} 
CATEDRAL Tomada: Revista de crítica literaria latinoamericana / Journal of Latin American Literary Criticism

Pensar con sonidos. Los universos musicales en El Trino del Diablo de Daniel Moyano.

herraduras de caballos, calabazas y caracoles. (El trino y otras modulaciones 72)

Villa Violín es un espacio ambiguo, ya que constituye una especie de gueto y destierro, a la vez que funciona como un refugio de libertad. Se trata de un caso extremo de construcción espacial de acuerdo a la asociación entre sonido, ritmo, leyes y organización social:

Villa Violín, aparentemente anárquica y marginada, tenía su propia congruencia. No había leyes, pero se regían por un conjunto de principios establecidos, mucho más rigurosos que los códigos: los de la música, que aplicados a las situaciones de la vida cotidiana funcionaban como la más perfecta de las constituciones. (El trino y otras modulaciones 71 )

Asimismo, opera como un resguardo de las libertades suspendidas, un reducto en el que se preserva el sentido de la música, aunque resulte prácticamente imposible ejecutarla. Los artríticos imaginan el sonido de la música porque carecen de instrumento -lo cual constituye, sin dudas, otra forma de tortura. Uno de los habitantes más antiguos de villa violín, aun sin poseer el instrumento dedicaba ocho horas diarias a la práctica y afirmaba: “Algún día [...] nuestra música volverá a tener sentido, habrá libertad y entonces podremos reintegrarnos al mundo." ( $E l$ trino y otras modulaciones 68-69). De tal manera, nuevamente vemos cómo se textualiza la noción de una música del universo, abstracta e inaudible, cuya captación es solo posible por el intelecto, y su correspondencia con el orden social y el equilibrio entre individuo y universo.

En ese espacio, los músicos "componían su propia música donde practicaban la para otros temible libertad" (El trino 60). De tal manera, existe una concordancia entre la libertad expresiva y la libertad ciudadana, en su organización política y social. La libertad estética permite la vivencia de otras prácticas de 
composición, interpretación, escritura y recepción, como también la experimentación con las fuentes sonoras en búsqueda de nuevos sonidos, nuevos materiales y el desarrollo de un nuevo lenguaje: "cada músico anotaba el esquema musical elegido con la notación que se le ocurriese" (El trino 61). Sus prácticas musicales vanguardistas y no convencionales propician asimismo la anulación de las fronteras entre compositores e intérpretes, y a su vez entre éstos y el público, ya que los conciertos se realizan en la calle con la participación de todos los habitantes.

Desde luego, esa libertad es mirada con recelo y sospecha por la cultura oficial y académica, que considera las obras de los artríticos como "subversivas" y a sus compositores como sujetos que intentan llegar al Teatro Colón a través de “medios capciosos". A la inversa, para los músicos de Villa Violín, el Teatro Colón era una "especie de infierno metafísico", una "sala de juegos musicales extranjera" (El trino 63). El Teatro Colón condensa una serie de símbolos y valores contrarios a los expresados por los músicos confinados en Villa Violín: reúne tradición musical europea en un espacio restringido a los sectores de elite, símbolo de pertenencia a un sector poderoso económico, político, social y cultural. Representa un lugar de pertenencia de una clase social, la oligarquía, que se concibe a sí misma como la única capacitada para dirigir los destinos del país, y que en la novela se asocia directamente con el gobierno militar.

\section{A modo de conclusiones}

El recorrido realizado ha permitido indagar y comprobar las posibilidades narrativas que habilita el funcionamiento dialógico e interdiscursivo entre literatura y música. El discurso musical coadyuva en la representación de un mundo complejo, por momentos absurdo e inexplicable. Las referencias e intertextos musicales constituyen igualmente un recurso para hablar de otros temas traspasando los márgenes del sentido estrictamente musical para irradiar todas las 
líneas de sentido allí presentes y, en ocasiones, imprimiendo un sentido otro, a menudo contrario, a lo que se está presentando. Ello permite en forma a veces más veladas o más explícitas cuestionar, criticar y denunciar situaciones como la falta de libertad, el exilio, la persecución política e ideológica, la violencia y la tortura, como también las estructurales desigualdades económicas entre la capital y las provincias del interior del país.

Las dos versiones de la novela actúan a la manera de dos voces, en cuyo contrapunto pueden leerse los cambios operados por una reescritura mediada por el tiempo, la distancia, y el dolor provocado por el destierro y el exilio. Mientras en la primera versión se muestra en forma irónica, crítica y paródica la convulsionada situación social, política e institucional del país, en la segunda versión, en cambio, el tono humorístico y lúdico cede lugar a una mirada más pesimista y desencantada.

A partir de allí se advierte la significación de esta novela en el contexto de la historia política en la Argentina de los años 1970, como también concretamente en la trayectoria de su autor, ya que su escritura constituyó uno de los motivos por los que recibió amenazas y apremios ilegales previos al exilio. Asimismo, esta novela permite percibir las formas veladas por las que a través de diversas referencias e intertextos musicales, la escritura da cuenta de la situación de opresión, violencia, falta de libertad y de esperanza manifestando una posición crítica frente a ello, ya sea mediante la ironía, el humor o la parodia.

La representación de un escenario social fragmentario, complejo, considerado desde distintos puntos de vista y enunciado desde distintos lugares se construye mediante un lenguaje saturado ideológicamente, atravesado por una lógica de oposiciones: amigos/enemigos, lo aceptable/lo prohibido, libertad/censura, obediencia/ subversión, sumisión/ transgresión, centros/periferias. En ese contexto deben leerse los tópicos del desarraigo, del exilio, de la falta de libertad y la censura, junto a las ironías y parodias sobre la historia argentina presentes en ésta y otras novelas de Moyano.

En el trayecto de lectura realizado mostramos cómo las concepciones desarrolladas en torno a la música de las esferas y la concepción de una armonía 
universal, operan en la novela como la búsqueda de una unidad primigenia con la naturaleza y el universo que funciona como paraíso perdido y utopía, mientras que los mitos en torno al poder mágico del sonido y del artista van señalando un conjunto de rasgos que llevan a una posición ambivalente frente a la música y los músicos. Así, se presenta una doble valoración que oscila entre lo celestial y lo demoníaco; entre considerarla un adorno o un instrumento de poder; entre concebirla inofensiva o peligrosa y "subversiva". Ante ello -y esto se muestra acabadamente en la novela- emergen diferentes mecanismos de control y regulación, dadas las sospechas y la consideración de sus efectos en los oyentes.

En las sospechas que genera el poder de la música y, en especial, en la ambivalente concepción del artista ya sea como un ser vulnerable y débil, o bien como un ser potencialmente peligroso, se fundan las razones para su control. La novela presenta las complejidades de tal concepción, sus tensiones y contradicciones, las posibilidades que van desde el control sobre la música hacia la liberación solo posible a través de ella. Entre atadura/libertad y control/liberación como tensiones irresolubles, la escritura apuesta decididamente por la capacidad del arte -tanto literario como musical- para registrar la multiplicidad, ser el receptáculo de las aspiraciones, los conflictos y las utopías de una época, convirtiéndose en un dispositivo privilegiado de la memoria y de la acción política. 
CAtEdral Tomada: Revista de crítica literaria latinoamericana / Journal of Latin American Literary Criticism Pensar con sonidos. Los universos musicales en El Trino del Diablo de Daniel Moyano.

\section{Bibliografía}

AAVV. Diccionario Enciclopédico de la música. Barcelona: Rombo, 1996.

Downs, Philip. La música clásica. Madrid: Akal, 1998.

Bajtín, Mijaíl. Teoría y estética de la novela. Madrid: Taurus, 1989.

Balestrino, Graciela. "Teoría de la reescritura". El bisel del espejo. La reescritura en el teatro contemporáneo español e hispanoamericano. G. Balestrino y M. Sosa, Editoras. Salta: CIUNSa/CeSICA, 1997. 27-62.

Barei, Silvia. De la escritura y sus fronteras. Córdoba: Alción Editora, 1991.

Corona Martínez, Cecilia. Literatura y música. Confluencias en la obra de Daniel Moyano. Córdoba: Editorial Universitas, Facultad de Filosofía y Humanidades, Universidad Nacional de Córdoba, 2005.

Fisas, Carlos. Intimidades de la Historia. Barcelona: Plaza \& Janés Editores, 1996.

Fubini, Enrico. Estética de la música. Madrid: Machado Libros, 2004.

Gil Amate, Virginia. Daniel Moyano: la búsqueda de una explicación. Oviedo: Departamento de Filología Española, Universidad de Oviedo, 1993.

Gilio, María Ester. "La música que brota de la tierra" (Entrevista a Daniel Moyano). Conversaciones. Buenos Aires: Ediciones de La Flor, 1986. 67-78.

Latham, Alison. Diccionario Oxford de la Música. México: Fondo de Cultura Económica, 2008.

López, Irene. "Un diálogo literario-musical en "Johann Sebastian Bach estorbado por sus hijos" de Egdardo Pesante". Relecturas, reescrituras. Articulaciones discursivas. Daniel Altamiranda, Editor. Buenos Aires: Universidad de Buenos Aires, Instituto "Ricardo Rojas", 1999. 614-619.

---. Alejo Carpentier. Los ritmos de una escritura entre dos mundos. Salta: Editorial de la Universidad Nacional de Salta, 2006. 
---. "Relaciones entre música y literatura. Notas para un encuentro". Tramos y Tramas. Culturas, Lenguas, Literaturas e interdisciplina. Estudios comparativos. Rosario: Laborde Libros, 2008. 273-281.

---. "Música, memoria e identidad en Un silencio de corchea de Daniel Moyano". Anales de Literatura Hispanoamericana 41 (2012): 365-377.

Llinás, Julián. La música a través de la historia. Barcelona: Salvat, 1984.

Malcuzinsky, M. Pierrette. "Interdiscursividad textual". Sociocriticism XVII No 1 y No 2. Montpellier: Ed. Du Cers, 2002, 29-46.

Moyano, Daniel. El trino del diablo. Buenos Aires: Sudamericana, 1974.

---. El trino del diablo y otras modulaciones. Rosario: Fundación Ross y Tropo Editores, 2012.

Rowell, Lewis. Introducción a la filosofía de la música. Barcelona: Gedisa, 1996. 